\title{
TRANSPORTING OBESE PERSONS USING AN EVACUATION PAD
}

\section{Tatiana Verešová ${ }^{1}$ and Jozef Svetlík ${ }^{2}$}

\begin{abstract}
Obesity is not only a medical illness but also a cosmetic problem. Obesity can be defined by the BMI index, which is not very accurate. The ABSI index, which includes BMI, the person's waist circumference, and their height may be used to more accurately determine obesity. Time is very important in saving people's lives, especially in emergencies. The rescue time for obese people is even longer - often much longer - than for other disabled people. This is because more rescuers are needed, problems arise when they have to go through the door or go up and down stairs. For the evacuation of obese people, evacuation pads located under the mattress are often used. Evacuation pads are used, for example, by hospitals or social service homes. Evacuation pads are designed for use by nurses, other emergency staff, or caretakers. In this exercise, four people were used - two nurses and two firemen. To find out the advantages and disadvantages of the evacuation pad, we performed a tactical exercise.

During the tactical exercise, the victim was evacuated by a single nurse, then by two nurses. After that, the victim was rescued by one firefighter and then two firefighters. This research is relevant to aspects of the rescue of immobile obese people with a special evacuation aid. It demonstrates the advantages and disadvantages of an evacuation pad based on actual tactical rescue exercises.
\end{abstract}

UDC Classification: 364-4, DOI: https://doi.org/10.12955/pss.v1.83

Keywords: rescue, evacuation pad, obese person

\section{Introduction}

Obesity is not only a medical illness but also a cosmetic problem. Obesity is on the rise and when an obese person's life is at risk, their rescue and transport complicate the iask. Rescuers, often women, may not have enough strength to lift the victim and transport them to the outpatient clinic. In this case, they call firefighters to assist. Up to 3-4 firefighters are used to remove and transport an obese person. To facilitate the transport of obese people in hospitals and social services homes, they use evacuation pads, which are pre-installed under each person's mattress. According to the manufacturer, the evacuation of an obese person should be managed by one nurse. The advantage of the evacuation pad is that it is easy to handle through the hallway and stairs. The victim is also evacuated with a mattress, pillow, and blanket.

\section{Obesity}

Obesity is a chronic disease and the condition reflects excessive storage of energy reserves in the form of fat for various reasons. Obesity occurs when energy intake is greater than expenditure. The reason is most often a combination of higher energy intake, lack of exercise, hereditary and psychological influences, and nutritional habits formed during childhood - the so-called primary obesity. It is rarely caused by other diseases, e.g., endocrine diseases, mental illness, like depression, bulimia, congenital diseases, or medicines (Glatz, 2019).

Obesity is defined according to several objective criteria. Comparisons with tables of average weight by age and height are often used. Most often, the body mass index (BMI) is calculated according to Formula 1:

$$
B M I=\frac{\text { mass }(\mathrm{kg})}{\text { height }^{2}(\mathrm{~m})}
$$

The average BMI is 22.4 for men and 22.5 for women. Obesity is defined as a BMI of 30 or more. More than half of the body fat is subcutaneous (Verbovská, et al., 2019). While central obesity is associated with metabolic and cardiovascular diseases (Glatz, 2019). The amount of abdominal fat can be determined by the circumference of the belt (Janssen, et al., 2002). The circumference of one's waist is positively correlated with abdominal fat content. The circumference of the waist is measured in a horizontal plane in the middle of the distance between the upper edge of the lumbar bone and the lower edge of the last rib (Lohman, 1988). The WHO's classification of obesity is shown in Table 1.

\footnotetext{
${ }^{1}$ University of Žilina, Faculty of Safety Engineering, Department of Fire Engineering, tatiana.veresova @ fbi.uniza.sk

${ }^{2}$ University of Žilina, Faculty of Safety Engineering, Department of Fire Engineering, jozef.svetlik@fbi.uniza.sk
} 


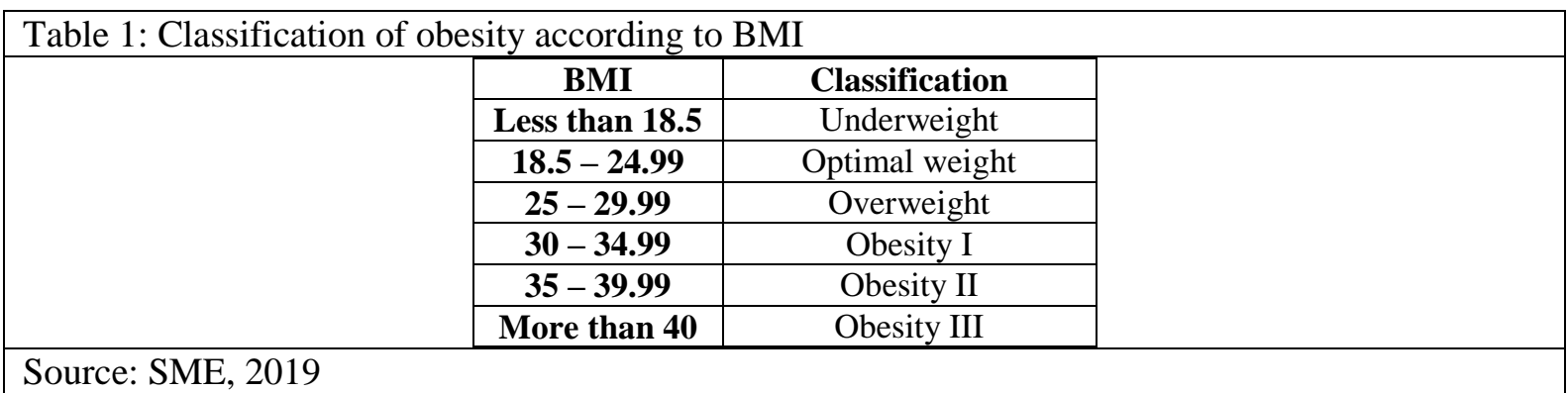

The BMI is a statistical tool and the clinical condition may differ from the significance of the measured BMI value in particular individuals. For example, a bodybuilder can have a BMI of over 30 and still not be obese, because the high index value is due to a large amount of muscle mass. On the other hand, older people with a small amount of muscle may be obese from a health point of view, although their BMI may rank them as having an ideal body weight (Glatz, 2019).

Physicians more accurately assess body weight and general condition of the body by using tests that measure the thickness of subcutaneous fat or by impedance measurements. Other important factors are blood pressure, cholesterol level, and physical activity. Poor diet, excessive alcohol intake, or smoking may also affect the outcome (Glatz, 2019).

According to the latest International Diabetes Federation (IDF) criteria, central obesity is defined by the perimeter of the circumference of a patient's waistline, as applied to a population of Europeans in Table 2.

\begin{tabular}{|l|l|l|l|}
\hline \multicolumn{4}{|l|}{ Table 2: Classification of obesity using waist circumference } \\
\hline \multirow{4}{*}{} & Waist circumference & Increased risk & High risk \\
\cline { 2 - 4 } & Women & $>80 \mathrm{~cm}$ & $>88 \mathrm{~cm}$ \\
\cline { 2 - 4 } & Men & $>94 \mathrm{~cm}$ & $>102 \mathrm{~cm}$ \\
\hline
\end{tabular}

The formula for a more accurate calculation of obesity is contained in A Body Shape Index (ABSI). The body shape index combines BMI, waist circumference, and height. It's more complex calculation provides increased accuracy in the final results. The body shape index is calculated using Formula 2 (Glatz, 2019).

Benefits of ABSI:

$$
A B S I=\frac{\text { Waist circumference }}{B M I^{2 / 3} \times \text { height }^{1 / 2}}
$$

- more accurate than the well-known BMI index;

- takes into account waist circumference;

- shows the amount of visceral fat in the body;

- differs in the amount fat contributes to weight vs muscles; and

- determines the degree of disease risk for obesity-related diseases (Glatz, 2019).

Application practice uses the term "oversized person" for very obese people. Firefighters and rescuers often encounter this concept. One obese or "oversized person" can weigh less than $100 \mathrm{~kg}$ while another person could weigh more than $150 \mathrm{~kg}$ before being considered obese.

In the case of rescuers, when two or three rescuers go to such a person, it is also important whether it is a man or a woman and their maximum possible load weight, which is determined according to Government Regulation no. 281/2006 Coll. on the minimum safety and health requirements for the manual handling of loads. The maximum weight for a woman's load is $15 \mathrm{~kg}$, whereas, the maximum weight of a man's load is $50 \mathrm{~kg}$. This weight decreases with increasing age. In addition to the maximum weight of the load, it is also important whether the technical means of pickup and transport of a person can accommodate the load capacity of the person.

\section{Evacuation pad}

Depending on the purpose of use, the evacuation pad should ensure the rapid and safe evacuation of the person in the event of a fire or other hazard. It is applied mostly in hospitals or social services facilities. 
According to the manufacturer, successful evacuations can be completed by every worker who has received the standard training. The evacuation pad is non-combustible, very durable, and practically indestructible during normal use. After simply grasping the evacuation pad, one person can evacuate and rescue a person. The evacuation pad can be safely passed through broken glass. The evacuated person is fastened with Velcro straps, the head is protected by a pillow, and the mattress itself (Konárik, 2019).

Advantages of the evacuation pad as stated by the manufacturer:

- easy installation;

- fixed handles for gripping;

- Velcro fasteners for securing a person;

- it is placed under the person's mattress

- it protects the entire surface of the mattress from below;

- it has safety handles on all sides of the pad;

- it has a system of mattress pad holders;

- it has a minimum load capacity 140 kg (Konárik, 2019); and

- the dimensions of the evacuation pad are 900 x 2,000 mm (Konárik, 2019).

Advantages and disadvantages of the evacuation pad.

When using an evacuation pad, there are advantages and disadvantages, which are shown in Table 3.

\begin{tabular}{|l|c|c|}
\hline \multicolumn{2}{|c|}{ Table 3: Advantages and disadvantages of the evacuation pad } \\
\hline \multirow{4}{*}{ ADVANTAGES } & DISADVANTAGES \\
\cline { 2 - 3 } & pre-applied & difficult handling for nurses \\
\cline { 2 - 3 } & one rescuer for one rescued person & rapid wear \\
\cline { 2 - 3 } & easy walk upstairs & $\begin{array}{c}\text { difficulty passing through } \\
\text { door openings }\end{array}$ \\
\cline { 2 - 3 } & load capacity (min. $140 \mathrm{~kg}$ ) & $\begin{array}{c}\text { difficulty handling in } \\
\text { cramped living spaces }\end{array}$ \\
\hline Source: Author
\end{tabular}

According to the manufacturer, a person can be rescued with an evacuation pad by a single nurse. The procedure for a rescue with an evacuation pad is the evacuation pad must be applied in advance placed under the mattress of the victim. The person must have a pillow under their head and a covering blanket, which they must wear throughout the evacuation. The nurse (or paramedic) uses security straps to pull the victim as far into the cross as possible to wrap the edges of the mattress as close as possible to the victim's body. The affected person keeps his hands next to his body. Subsequently, using the handle located on the side of the victim's feet, the nurse or paramedic holds the evacuation pad and pulls the victim along the ground with the mattress.

When rescuing obese people with an evacuation pad, the strength of the rescuer is very important. One nurse may not have sufficient strength to properly secure the victim. This was also shown during tactical exercises using the evacuation pad. The biggest problem for rescuing the victim was the placement of the furniture in the room and the route that a mattress must travel through door openings. The door opening measured $90 \mathrm{~mm}$, which complicated the passage of the rescuer and the victim with a mattress and manipulation (turning) in a small hallway. The victim was drug along the ground the entire time. The advantage of effectuating an evacuation using an evacuation pad is that traversing stairs was smooth and simple. The victim had a soft mattress under him all the time.

Subsequently, the evacuation of a victim was tested using the help of two nurses. They secured the victim on the pad better than when only one nurse was used. Both nurses also helped each other in pulling the victim. However, the evacuation was still not fast and efficient enough, as the nurses did not have enough combined strength to optimize the evacuation. Upon arrival at the destination with the disabled person, the nurses were short of breath and tired. The evacuation distance of the victim was $22 \mathrm{~m}$ and down some stairs. The weight of the evacuee was only $70 \mathrm{~kg}$, but still caused problems for the two nurses.

After the tests using the nurses, firefighters were used. The first rescue was done by one fireman followed by the use of two firemen at the same time. The weight of the victim was $97 \mathrm{~kg}$. Both the rescue by the single and then the team of two firefighters were much more effective than the tests using the 
three nurses. Two firefighters fixed the affected person very strongly and pulled the mattress edges together as close as possible. In critical areas, such as the door opening, crossing a narrow corridor, moving in and out of bed, they knew very well how to conduct the rescue of the victim, and everything proceeded expeditiously. When the rescue was carried out by one firefighter, he had problems only in the most critical places. The biggest problem, as in most rescue attempts, occurred when negotiating a corridor. This problem was due to the poor construction of the handles.

The simplest rescue of the victim with an evacuation pad was two firefighters who helped each other, especially in critical areas of the building.

The measured evacuation (rescue) times are shown in Table 4.

\begin{tabular}{|l|c|c|c|c|c|}
\hline \multicolumn{1}{|l|}{ Table 4: Measurement results } \\
\hline \multirow{5}{*}{} & Rescue a person & $\mathbf{1}$ & $\mathbf{2}$ & $\mathbf{3}$ & $\mathbf{4}$ \\
\cline { 2 - 7 } & $\begin{array}{c}\text { Person's weight } \\
{[\mathrm{kg}]}\end{array}$ & 70 & 70 & 97 & 97 \\
\cline { 2 - 7 } & Rescuers & 2 nurses & 1 nurse & 1 firefighter & 2 firefighters \\
\cline { 2 - 6 } & Rescue start time & $10.01 \mathrm{~h}$. & $10.24 \mathrm{~h}$. & $10.28 \mathrm{~h}$. & $10.34 \mathrm{~h}$. \\
\cline { 2 - 6 } & Rescue end time & $10.08 \mathrm{~h}$. & $10.28 \mathrm{~h}$. & $10.31 \mathrm{~h}$. & $10.36 \mathrm{~h}$. \\
\cline { 2 - 6 } & Total time [min.] & 7 & 4 & 3 & 2 \\
\hline Source: Author
\end{tabular}

The graph of the weight of the helper and the length of the rescue is shown in Figure 1.

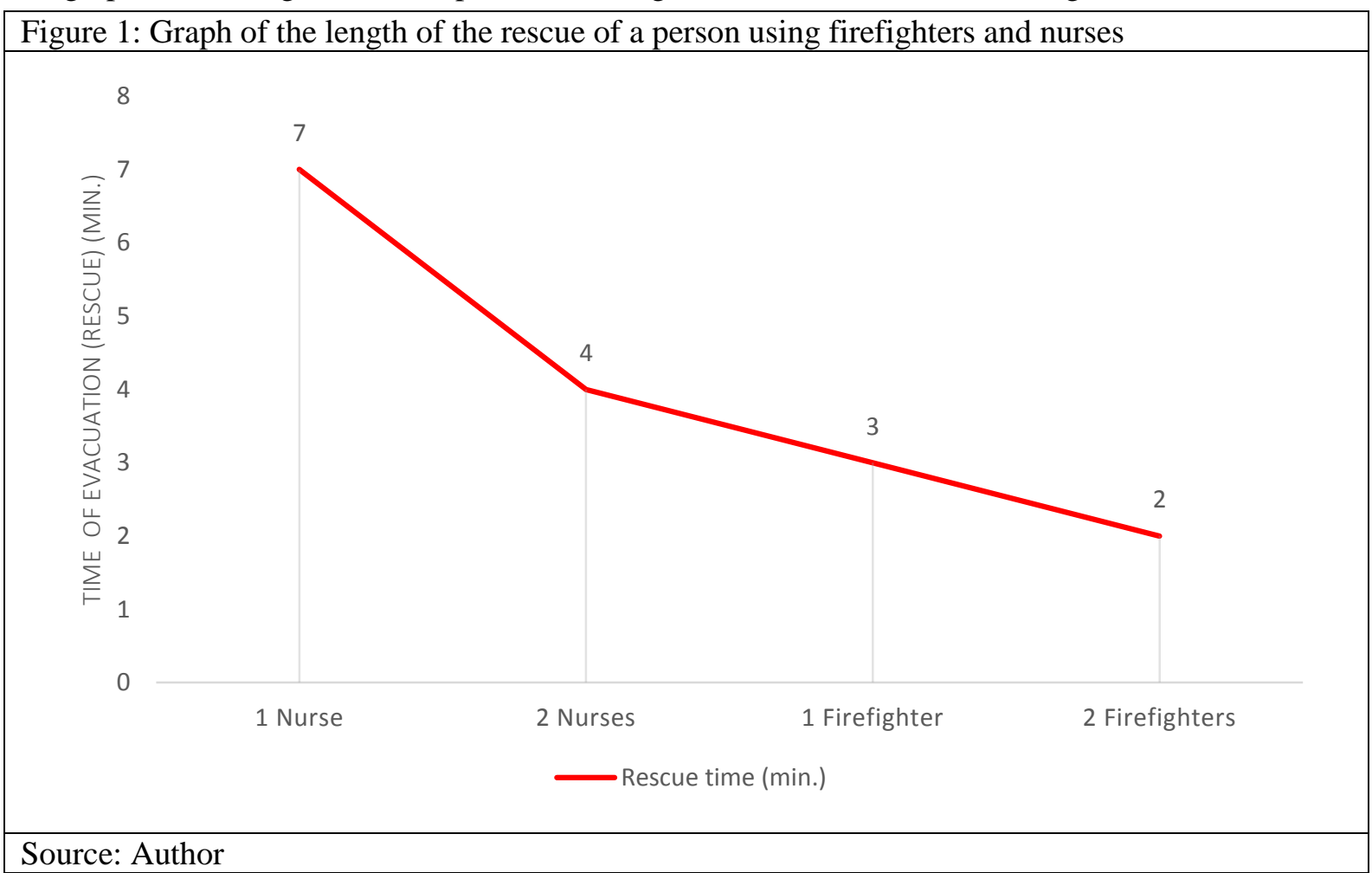

According to Figure 1, the longest-lasting evacuation was with one nurse and the shortest was the rescue with two firefighters. The main difference was that the two firefighters were able to easily navigate critical crossings.

\section{Conclusion}

Obesity is a very serious disease. Problems arise when an obese person needs to be transported from their home to the hospital, oftentimes in an emergency. In such cases, firefighters are called in to assist. Rescuing an obese person is physically demanding with several restrictions when passing through normal openings in the building. In hospitals and social service homes, they have pre-applied evacuation pads under each mattress. Evacuation pads are used to transport the victim efficiently. The advantage of evacuation pads is that they are located under the mattress and the evacuation is also performed with the mattress and the blanket. The evacuation pad is preferably intended for the evacuation of a disabled 
person by one nurse. When performing tests using nurses, it was found that one nurse is sometimes not able to evacuate the victim on their own. Nurses are sometimes not strong enough to secure the victim/patient properly when working solo. When there is a failure to properly secure the patient to the mattress/evacuation pad, the mattress will not be wrapped tightly enough around the patient's body, which consequently restricts easy passage through doors and other openings between rooms. Pulling the disabled person out of bed also places higher demands on the nurses. It is necessary to close the mattress tightly so that the mattress and the victim can be pulled out of bed and through low barriers using the evacuation pad and mattress. The best and fastest rescue of a victim was performed by two firefighters, who secured the victim most firmly (of all the tested procedures). In critical places such as passing through door openings, getting out of bed, and maneuvering through narrow passages, they were very eager to help and the rescue proceeded effectively and quickly.

\section{References}

BMI - body mass index. (2019, May 3). Retrieved from https://mdiet.blog.sme.sk/c/366550/bmi-body-mass-index.html Glatz, J. (2019). Obezita ako rizikový faktor zamestnancov. [Obesity as a risk factor for employees.] (page7). Košice: Technical University of Košice.

Janssen I., Heymsfield S., Allison D., Kotler D., Ross R. (2002). Body mass index and waist circumference independently contribute to the prediction of nonabdominal, abdominal subcutaneous, and visceral fat. Am J ClinNutr 2002;75:683-8.

Konárik, M. (2019 February 14). Personal Interview.

Lohman T. (1988). Anthropometric Standardization Reference Manual. Human Kinetics.

Nariadenie vlády číslo 281/2006 o minimálnych bezpečnostných a zdravotných požiadavkách pri ručnej manipulácii s bremnami [Government Regulation No. 281/2006 Coll. Of the Slovak Republic about the minimum safety and health requirements for the manual handling of loads (2006).]

Verbovská, J., Karaš, J., Kaššay, K., Požonská, M., Miženková, L'. (2019, August 10). Transport obéznych pacientov. [Transport of obese patients.] Retrieved from

https://www.unipo.sk/public/media/files/docs/fz_veda/svk/dokument_165_31.pdf 